\title{
Cam İpliğinden Farklı Desenlerde Üretilmiş Atkılı Örme Ribana Kumaşların Fiziksel, Yapısal ve Hava Geçirgenliği Özellikleri
}

\author{
Mehmet Erdem İNCE ${ }^{*}$, Kıymet SAVCI GÜNEŞ ${ }^{1}$ \\ ${ }^{1}$ Gaziantep Üniversitesi, Mühendislik Fakültesi, Tekstil Mühendisliği Bölümü, Gaziantep \\ (ORCID: 0000-0001-7537-9172) (ORCID: 0000-0001-6263-6512)
}

\begin{abstract}
$\ddot{O} \mathbf{z}$
Bu çalışmada cam ipliğinden $1 \times 1,2 \times 2$, İngiliz ve balıkçı ribana desenlerinde üretilmiş atkılı örme kumaşların fiziksel, yapısal ve hava geçirgenliği özellikleri bu kumaşlarla güçlendirilmiş polimer matrisli kompozit malzeme üretimi düşünülerek mercek altına alınmıştır. $2 \times 2$ ribana deseni hem makine üzerinde hem de makineden alındıktan sonra, desen kaynaklı kumaş iç geriliminin bir neticesi olarak, ilmek sırası yönünde dramatik bir şekilde daralmıştır. Bu daralma sıkı ve sert tutumlu bir kumaş yapısı ortaya koymuştur. Diğer yandan balıkçı ribana deseninde her iki yüzde yer alan askı ilmekler, kumaş makineden alındıktan sonra, ilmek çubuklarının saat ibreleri yönünde dönüp birbiri üzerine yuvalanmalarını sağlayarak kumaş boyunu kısaltmış ve sıkı bir yapı oluşturmuştur. Sıkı bir kumaş yapısına sahip olmalarından ötürü; $2 \mathrm{x} 2$ ve balıkçı ribana desenleri, $1 \mathrm{x} 1$ ve İngiliz ribana desenlerine kıyasla daha yüksek kalınlık, alansal yoğunluk ve ilmek yoğunluğu gösterirken, daha düşük bir ilmek uzunluğu sergilemiştir. En gevşek kumaş yapısına sahip olan 1x1 ribana deseni en yüksek hava geçirgenliğini sergilerken, en sert tuşeli ve sıkı yapılı 2x2 ribana deseni en düşük hava geçirgenliğini sergilemiştir. Hava geçirgenliği ile ilmek uzunluğu arasında en güçlü pozitif korelasyon gözlemlenirken, hava geçirgenliği ile ilmek sırası sıklı̆̆ arasında en güçlü negatif korelasyon gözlemlenmiştir. Bu çalışma, kumaş sıklığını ve buna bağlı olarak hava geçirgenliğini kontrol eden örgü desen parametresi değiştirilerek fark lif hacimsel oranlarında ve çeşitli mekanik özelliklere sahip cam ipliğinden atkılı örme kumaş takviyeli kompozitlerin üretilebileceğini göstermiş̧ir.
\end{abstract}

Anahtar kelimeler: Cam ipliği, Atkılı örme kumaş, Kumaş yapısal özellikleri, Kumaş hava geçirgenliği, Polimer matris kompozit

\section{Physical, Structural and Air Permeability Properties of Glass Yarn Weft Knitted Rib Fabrics from Different Patterns}

\begin{abstract}
In this study physical, structural and air permeability properties of weft knitted fabrics made of glass yarn with $1 \times 1,2 \times 2$, English and fisherman rib patterns were examined via considering the production of polymer matrix composites reinforced by these fabrics. As a result of the pattern-induced fabric internal tension, the $2 \times 2$ rib knit contracted dramatically in the course direction both while it was on the machine and after it was removed from the machine. This contraction produced a tight and firm fabric structure. On the other hand, after the fabric was taken from the machine, the tuck stitches on both sides of the fisherman rib pattern shortened the fabric length and formed a tight structure by rotating the loop bars clockwise and nesting them on each other. Due to their tight fabric structures; the 2x2 and fisherman rib patterns showed higher thickness, higher areal density, higher loop density, and lower loop length than 1x1 English rib patterns. While the 1x1 rib pattern with the loosest fabric structure exhibited the highest air permeability, the $2 \times 2$ rib pattern with the hardest touch and tight structure displayed the lowest air permeability. Although the strongest positive correlation was observed between air permeability and loop length, the strongest negative correlation was observed between air permeability and course density. This study showed that glass-yarn weft-knitted fabric reinforced composites with various fiber volume fractions and mechanical properties can be produced by changing the knit pattern parameter that controls the fabric tightness and accordingly the air permeability.
\end{abstract}

\footnotetext{
*Sorumlu yazar:eince@gantep.edu.tr,meince@ncsu.edu Geliş Tarihi: 25.08.2021, Kabul Tarihi: 15.11.2021
} 
Keywords: Glass yarn, Weft knitted fabric, Fabric structural properties, Fabric air permeability, Polymer matrix composite

\section{Giriş}

Atkılı örme kumaşlarda ilmeklerin iç içe geçmesiyle oluşan karmaşık ve üç boyutlu içyapı bu kumaşları tekstil kumaşları arasında benzersiz kılmaktadır. Kolaylıkla gerdirilebilir ve şekil alabilir olmaları bu kumaşların en büyük avantajlarından bir tanesidir. Kumaş deseni kumaşın fiziksel, yapısal özelliklerini ve kullanım performansını tayin etmektedir. Bu çalışma cam ipliğinden farklı desenlerde üretilmiş atkılı düz örme ribana kumaşların fiziksel, yapısal ve hava geçirgenliği özelliklerinin incelenmesi üzerinedir ve bu bağlamda gözden geçirilen literatür aşağıda verilmiştir.

Kane vd. [1] pamuk ipliğinden süprem ve ask1 ilmekli atkılı örme kumaşlar üretmiştir. Süprem kumaşa nazaran askı ilmekli kumaşlar daha yüksek kalınlık, alansal yoğunluk ve hava geçirgenliği sergilemiştir. İlmek uzunluğu kumaşın kalınlığını, alansal yoğunluğunu, sıra/çubuk/ilmek sıklığını, sıklık faktörünü ve patlatma mukavemetini düşürürken su emiciliğini ve hava geçirgenliğini arttırmıştır. Araştırmacılar genel olarak askı ilmeğinin kumaş özelliklerini iyileştirdiği sonucuna varmıştır.

Mikučionienè vd. [2 - 4] aramid ipliğinden ürettikleri süprem kumaşların tutuşa bilirlik ve konfor özelliklerini ilmek uzunluğu ve iplik kat sayısını değiştirmek suretiyle optimize etmeye çalışmıştır. İlmek uzunluğu yanma süresini azaltırken iplik kat sayısı arttırmıştır. Diğer taraftan uzun ilmekli ve düşük iplik kat sayılı kumaşlar daha yüksek hava geçirgenliği sergilemiştir. Bivainytè ve Mikučionienè [5] dış yüzeyinde pamuk veya bambu ipliğinin, iç yüzeyinde ise sentetik ipliğin yer aldığı atkılı örme vanize kumaşların hava ve su buharı geçirgenliğini incelemiştir. Aynı desene sahip kumaşlarda ilmek uzunluğu ile hava geçirgenliği arasında pozitif ve doğrusal bir ilişki gözlemlenirken, farklı desene sahip kumaşlarda bu ilişki gözlemlenmemiştir.

Ciobanu ve Filipescu [6] ham maddenin (akrilik ve polyester iplik), örgü deseninin (süprem, $1 \mathrm{x} 1$ ribana ve $1 \mathrm{x} 1$ ters örgü), kam ayarının ve iplik tansiyonunun atk1lı örme kumaşların gerilme mukavemeti özellikleri üzerine etkisini incelemiştir. Kumaşlar ilmek sırası ve ilmek çubuğu yönünde farklı davranırken kumaşların ilmek sırası yönünde gerilme mukavemetini etkileyen en etken girdi değişkeni olarak örgü deseni ön plana çıkmıştır. Çoruh [7] lif (pamuk/viskon ve pamuk/polyester) karışım oranı ve kam ayarının atkılı örme süprem kumaşlarda patlatma mukavemeti, hava geçirgenliği ve su buharı geçirgenliği üzerine etkilerini incelediği çalışmasında kumaşın tüm özelliklerini etkileyen ana faktör olarak ilmek uzunluğuna işaret etmiştir. Ciobanu vd. [8] atkılı örme sandviç kumaşlarda kam ayarının, bağlayıcı iplik tipinin (aramid veya keten iplik) ve atkı yatırım ipliğinin kumaş patlatma mukavemeti üzerine etkisini incelemiştir. İlmek uzunluğunun düşmesi ile birlikte kumaş patlatma mukavemeti artmıştır.

Uyanık vd. [9], Uyanık ve Topalbekiroğlu [10] pamuk ipliğinden ürettikleri atkılı örme kumaşlarda örgü tekrarı içinde yer alan askı ilmeklerinin sayısının ve pozisyonunun kumaşın patlatma ve boncuklanma dayanımını istatiksel olarak önemli seviyede etkilediğini ifade etmiştir. Kumaş özelliklerini etkileyen en etkin yapısal parametrenin ilmek uzunluğu olduğu ifade edilmiş ve ilmek uzunluğu ile kumaş patlatma mukavemeti arasında negatif bir ilişki tespit edilmiş̧ir. Küçük boyutlu örgü tekrarlarında çapraz konumlanmış askı ilmeklerinin kumaşı ilmek çubuğu yönünde kısaltarak kumaş sıklığını ve patlatma mukavemetini arttırdığı rapor edilmiştir. Askı ilmeği içeren kumaşların süprem kumaşa nazaran daha yüksek boncuklanma dayanımı sergilemesi askı ilmekli kumaşların gözenekli yapılarına atfedilmiştir.

İnce ve Yildirim [11] tek iğne yatağ kullanarak cam ipliğinden ürettikleri atkılı düz örme kumaşlarda farklı ilmek tiplerinin hava geçirgenliği ve patlatma mukavemeti üzerine etkisini incelemiştir. Makineden alınan askı ilmekli kumaşın dramatik bir şekilde kısalarak ilmek çubuklarının saat ibreleri yönünde dönmesi ve birbiri üzerlerine yerleşmeleri ilmek yoğunluğunu ve lif içeriğini arttırırken ilmek uzunluğunu azaltmıştır. Böylece askı ilmekli kumaş en düşük hava geçirgenliği ve en yüksek patlatma mukavemetini sergilemiş̧ir. Önceki çalışmalara istinaden pamuk ipliğinden üretilmiş askı ilmeğinin hava geçirgenliğini arttırdığı ve patlatma mukavemetini düşürdüğü rapor edilirken bunun aksine kendi çalışmalarında ise cam iplik ask1 ilmeklerin hava geçirgenliğini düşürdüğü ve patlatma mukavemetini arttırdığ ifade edilmiştir.

Üç boyutlu birbiri içine geçmiş gözenekli ilmeklerden, diğer tekstil kumaşlarına nazaran daha düşük maliyetlerle üretilen, gerdirilebilir ve dökümlü atkılı örme kumaşlar teknik tekstil 
uygulamalarında avantaj sağlamaktadır. Atkılı örme tekniği ile sıvı kompozit kalıplama uygulamalarına yönelik üç boyutlu, esnek, kolay kalıplanabilir, geçirgen ve (dokusuz ve dokuma kumaşlara nazaran) darbe dayanımı daha yüksek takviye kumaşı [12-15] üretmek mümkündür.

Yapılan literatür taraması kumaş desen parametresinin ilmek uzunluğunu da kontrol etmek suretiyle atkılı örme kumaşların fiziksel özelliklerini ve kullanım performansını belirlediğini göstermiştir. Önceki çalışmalar bu gerçeği doğal ve/veya sentetik iplikler için incelemiştir. Ancak çift iğne yatağı kullanılarak cam iplikten örülmüş atkılı örme ribana kumaşların özelliklerini incelemeye yönelik özel bir dikkat sarf edilmemiştir

$\mathrm{Bu}$ çalışmanın amacı cam ipliğinden muhtelif ribana desenlerinde üretilmiş atkılı örme kumaşlarda desen parametresini değiştirme yoluyla kumaşın fiziksel ve yapısal özelliklerinin kontrol edilebileceği ve farklı lif hacimsel oranlarında (farklı kumaş sıklıklarında) kumaş takviyeli polimer matris kompozit malzeme üretilebileceğini göstermektir. Bu bağlamda, kumaş yapısal ve fiziksel özelliklerine ek olarak, kumaş yapısı sıklığının (lif hacimsel oranının) sayısal bir göstergesi olarak kumaş hava geçirgenliği performansı ölçülmüştür.

\section{Materyal ve Metot}

Tek kat iplik numaras 136 tex ve her bir lifinin çap1 9 mikron olan çoklu filament cam ipliğinden üç kat ipliği Brother KH-864 marka, elle çalışan, 5E inceliğe sahip, düz atkılı örme makinesine beslemek suretiyle kumaşlar üretilmiştir. Geleneksel tekstil uygulamalarında yaygın olarak kullanılan dört farklı kumaş deseni seçilmiştir. Şekil 1 seçilen atkılı örme kumaş desenlerinin teknik gösterimini ve elle çizilmiş görüntülerini içermektedir. Şekil 2 ise gerçek kumaş desenlerinin makine üzerinde ilmek çubuğu yönünde gerdirilmiş halde ve masa üzerinde serbest halde çekilmiş fotoğraflarını göstermektedir.

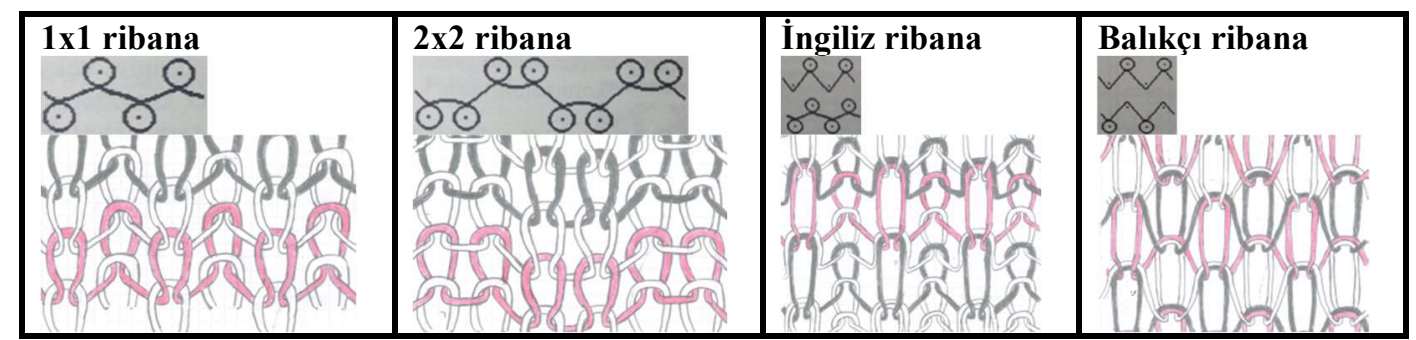

Şekil 1. Örgü desenlerinin teknik gösterimleri ve elle çizilmiş görünümleri

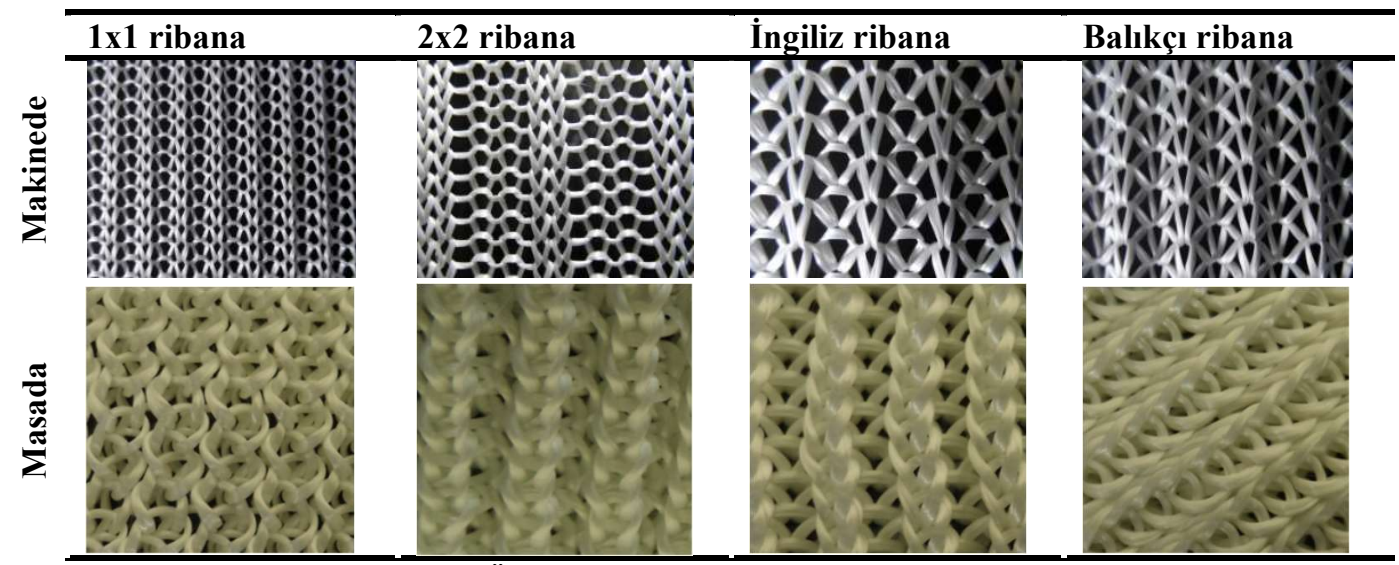

Şekil 2. Örgü desenlerinin gerçek görünümleri 


\subsection{Kumaşların fiziksel ve yapısal özelliklerinin ölçülmesi}

\subsubsection{Kalınlık}

Kumaş kalınlığı bask1 ayağ1 çapı $21,15 \mathrm{~mm}$ olan dijital kalınlık ölçer yardımıyla ölçülmüştür. Kumaşların hacimli ve teknik tekstil kumaşı olmasından dolayı kalınlık ölçümü 200 kPa basınç altında yapılmıştır.

\subsubsection{Alansal yoğunluk}

ASTM D3776 [16] standardına uygun olarak kumaşlardan özel bir kalıp kesici yardımıyla $5 \times 5 \mathrm{~cm}^{2}$ boyutunda kesilen parçaların ağırlıkları hassas terazide ölçülmüştür. Ölçülen kumaş alansal yoğunluğu ve kumaş kalınlığı değerlerinin Eşitlik (1)'de yerine konması yoluyla lif hacmi yüzdesi hesaplanmıştır. Eşitlik (1)'de yer alan $\boldsymbol{A}_{\boldsymbol{f}}, \boldsymbol{\rho}_{\boldsymbol{f}}$ ve $\boldsymbol{t}$ sembolleri sırasıyla kumaş alansal yoğunluğunu, lif hacimsel yoğunluğunu ve kumaş kalınlığını ifade etmektedir. Cam lifinin hacimsel yoğunluğu $2,5 \mathrm{~g} / \mathrm{cm}^{3}$ olarak kabul edilmiştir.

Lif hacmi yüzdesi $[\%]=\frac{A_{f}}{\rho_{f} * t} * 100$

\subsection{3. İlmek sırası ve ilmek çubuğu sıklığı}

İlmek sırası ve ilmek çubuğu sıklığı ASTM D8007 [17] standardına uygun olarak ölçülmüştür. İlmek yoğunluğu (bir $\mathrm{cm}^{2}$ 'lik alanda yer alan ilmeklerin sayısı) ilmek sırası ve ilmek çubuğu sıklık değerlerinin çarpımından hesaplanmıştır.

\subsection{4. İlmek uzunluğu}

İlmek uzunluğu ölçümünde BS 5441 [18] standardı takip edilmiştir. İlmek sırası yönünde 5 santimetrelik bir mesafede bulunan ilmekler sayılmış, daha sonra bu mesafe sökülmüş, gerdirilmiş ve uzunluğu bir cetvel yardımı ile ölçülmüsştür. Sökülen uzunluk ile ilmek sayısı arasındaki oran milimetre biriminden ilmek uzunluğu olarak kayıt altına alınmıştır.

\subsection{Kumaşların hava geçirgenliğinin ölçülmesi}

Kumaşların hava geçirgenliğinin ölçülmesinde SDL ATLAS M021 test cihazı kullanılmış ve ASTM D737 [19] metodu takip edilmiştir. Kumaş test alanı olarak $20 \mathrm{~cm}^{2}$ ve basınç düşümü olarak $200 \mathrm{~Pa}$ seçilmiştir. Tüm grafiklerin çiziminde ve verilerin analizinde JMP ${ }^{\circledR}[20]$ yazılım paketinin deneme sürümü kullanılmıştır.

\section{Bulgular ve Tartışma}

\subsection{Kalınlık, alansal yoğunluk ve lif hacmi yüzdesi}

Şekil 3 ve Tablo 1 örgü deseninin kalınlık, alansal yoğunluk ve lif hacmi yüzdesi üzerine olan etkilerini göstermektedir. İngiliz ve balıkçı ribana örgü desenlerindeki askı ilmekleri kumaş makineden çıkarıldıktan sonra hem en hem de boy yönünde daralmaya neden olarak kalınlığ 1 arttırmıştır. Önceki çalışmalarda tek iğne yatağı kullanılarak pamuk ipliğinden üretilen atkılı örme kumaşlarda da ask1 ilmeğinin sayısı ve pozisyonu kumaşın fiziksel özelliklerini ve kullanım performansını önemli ölçüde etkileyerek kalınlık ve alansal yoğunluğu arttırmıştır [1, 9, 10]. Benzer şekilde İnce ve Yıldırım [11] cam ipliğinden tek iğne yatağı kullanarak ürettikleri atkılı örme kumaşlarda askı ilmeğinin kumaş kalınlığını ve alansal yoğunluğunu arttırdığını gözlemlemiş ve bu artışı ilmek çubuklarının saat ibreleri yönünde dönerek yuvalanmalarına bağlamıştır.

2x2 ribana örgü deseninde düz ve ters ilmek çubuklarının ikili ve ardışık yerleşimi kumaş iç gerilimini arttırmış ve bu iç gerilim de makineden çıkarılan kumaşın ilmek sırası (kumaş eni) yönünde dramatik bir şekilde daralmasına neden olmuştur. Böylece kumaş eni yönünde bir hayli daralan 2x2 ribana örgü deseni, 1x1 ribana örgü desenine kıyasla daha yüksek kalınlık sergilemiştir. İkili 
karşılaştırmalar balıkçı ve 2x2 ribana örgü desenleri arasındaki kalınlık farkının, İngiliz ve 1x1 ribana örgü desenleri arasındaki kalınlık farkı gibi, istatistiksel olarak anlamlı bir düzeye ulaşmadığını göstermiş̧tir. Desenden kaynaklı olarak düşük bir kumaş iç gerilimine sahip olan 1x1 ribana örgü deseni gevşek bir yapı ortaya koyup en düşük kumaş kalınlığı sergilemiştir. Benzer sonuçlar örgü deseninin kumaş alansal yoğunluğu ve lif hacmi yüzdesine etkisinde de gözlemlenmiştir. 2x2 ribana örgü deseni ve ask1 ilmek ihtiva eden örgü desenleri 1x1 ribana örgü deseninden daha yüksek alansal yoğunluk ve lif içeriği sergilemiştir. 


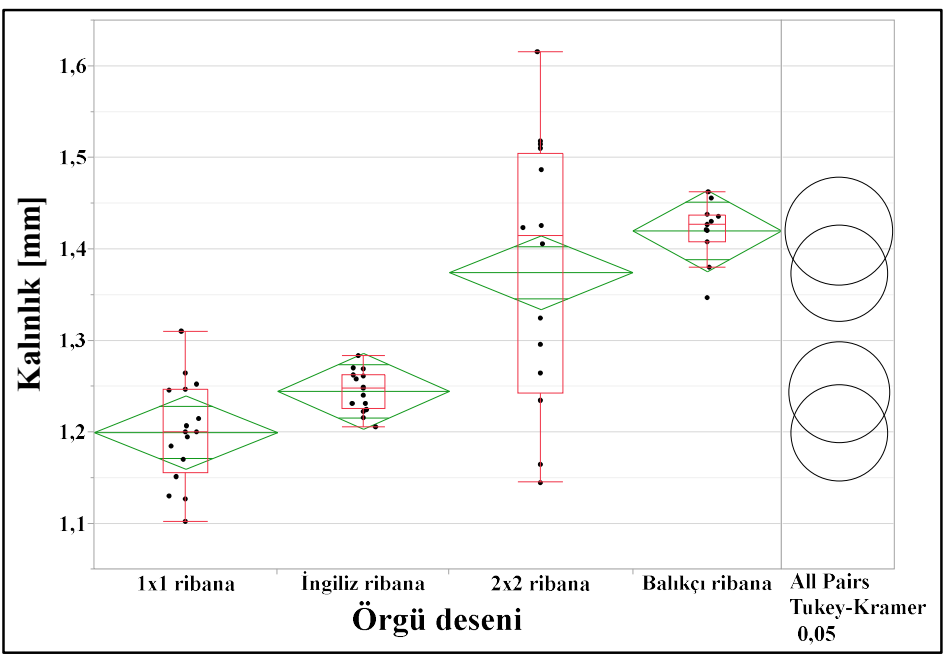

a

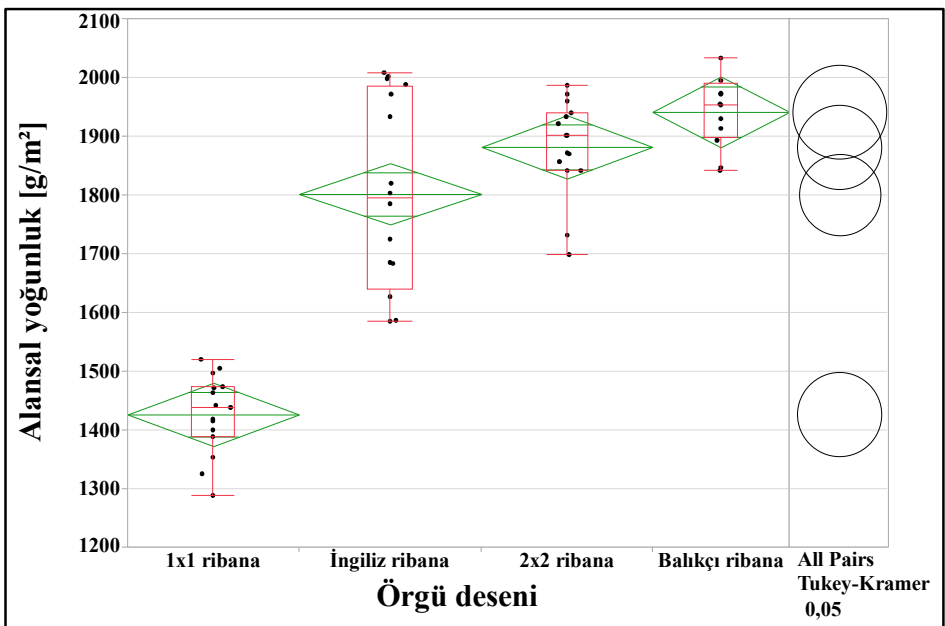

b

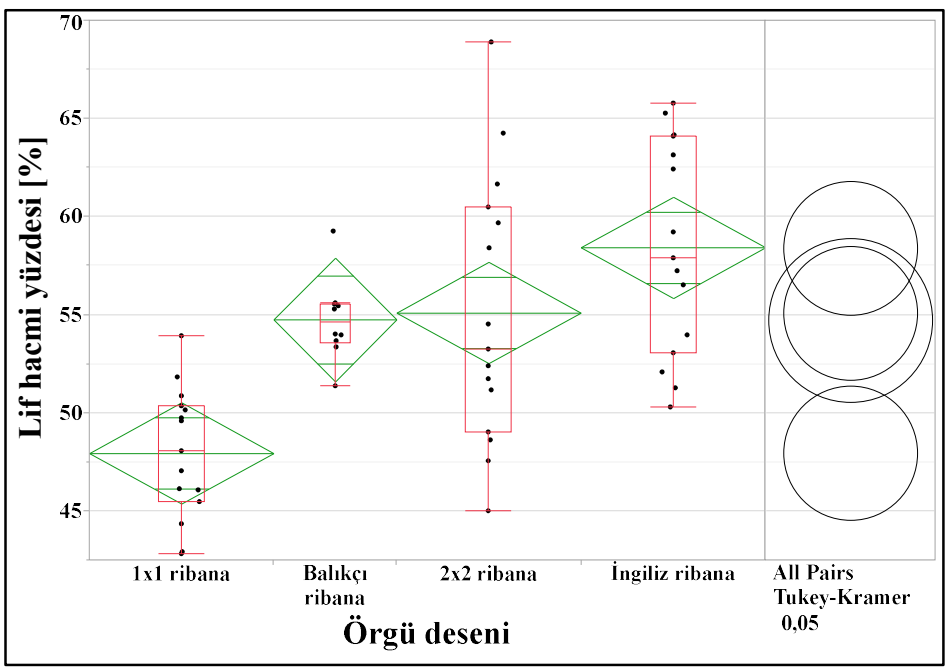

$\mathrm{c}$

Şekil 3. Örgü deseninin kalınlık (a), alansal yoğunluk (b) ve lif hacmi yüzdesi (c) üzerine etkisi

Not: Yeşil elmasların alt ve üst köşeleri arasındaki mesafe \% 95 güven aralığını temsil etmektedir. Her bir örgü deseni seviyesinin hesaplanan ortalama değeri için bir adet karșilaştırma dairesi sağ taraftaki sütunda verilmektedir. Önemli seviyede birbirinden farklı olan ortalamaları temsil eden daireler ya kesişmemekte ya da hafifçe kesişmektedir. 
Tablo 1. Örgü deseninin kalınlık, alansal yoğunluk ve lif hacmi yüzdesi üzerine etkisi

\begin{tabular}{|c|c|c|c|c|c|c|c|c|c|}
\hline Özellik & Örgü deseni & & & $\bar{n}$ & ort & SS & $\overline{\mathbf{A L}}$ & $\ddot{\mathbf{U} L}$ & p-değeri \\
\hline \multirow{4}{*}{$\begin{array}{l}\text { Kalınlık } \\
{[\mathrm{mm}]}\end{array}$} & Balıkçı ribana & $\bar{A}$ & & 13 & 1,42 & 0,03 & 1,40 & 1,44 & \multirow{4}{*}{$<0,0001$} \\
\hline & $2 \times 2$ ribana & $\mathrm{A}$ & & 16 & 1,37 & 0,14 & 1,30 & 1,45 & \\
\hline & İngiliz ribana & & B & 15 & 1,24 & 0,02 & 1,23 & 1,26 & \\
\hline & $1 \times 1$ ribana & & B & 16 & 1,20 & 0,06 & 1,17 & 1,23 & \\
\hline \multirow{4}{*}{$\begin{array}{l}\text { Alansal } \\
\text { yoğunluk } \\
{\left[\mathrm{g} / \mathrm{m}^{2}\right]}\end{array}$} & Balıkçı ribana & $\mathrm{A}$ & & 12 & 1941,78 & 59,18 & 1904,2 & 1979,4 & \multirow{4}{*}{$<0,0001$} \\
\hline & $2 \times 2$ ribana & A & B & 15 & 1881,99 & 82,08 & 1836,5 & 1927,4 & \\
\hline & İngiliz ribana & & B & 16 & 1801,83 & 161,47 & 1715,8 & 1887,9 & \\
\hline & 1x1 ribana & & & C 15 & 1426,46 & 66,99 & 1389,4 & 1463,6 & \\
\hline \multirow{4}{*}{$\begin{array}{l}\text { Lif hacmi } \\
\text { yüzdesi } \\
{[\%]}\end{array}$} & İngiliz ribana & $\mathrm{A}$ & & 15 & 58,41 & 5,45 & 55,40 & 61,43 & \multirow{4}{*}{$<0,0001$} \\
\hline & $2 \times 2$ ribana & A & & 15 & 55,10 & 6,84 & 51,31 & 58,88 & \\
\hline & Balıkçı ribana & A & & 10 & 54,74 & 2,05 & 53,27 & 56,21 & \\
\hline & 1x1 ribana & & B & 15 & 47,94 & 3,31 & 46,11 & 49,78 & \\
\hline
\end{tabular}

Not: Aynı alfabetik büyük harfle birleştirilmeyen seviyeler birbirlerinden önemli seviyede farklıdır $(\alpha=0,05)$. n: ölçüm sayısı, ort: ortalama, ss: standart sapma, AL: alt limit, ÜL: üst limit. Limitler \% 95 güven seviyesine göre tesis edilmiştir. 0,05'den küçük olan p-değerleri en az iki seviye arasındaki farkın istatistiksel olarak önemli olduğunun bir ifadesi olup kırmızıya boyanmıştır.

\section{2. İlmek sırası sıklığı, ilmek çubuğu sıklığı ve ilmek yoğunluğu}

Örgü deseni ilmek sırası sıklığı, ilmek çubuğu sıklığı ve ilmek yoğunluğu üzerinde istatistiksel olarak önemli bir ol oynamış ve 2x2 ribana örgü deseni bu özellikler açısından diğer desenleri gölgede bırakmıştır (Şekil 4, Tablo 2). 2x2 ribana örgü deseni makineden çıkarıldıktan sonra ilmek sırası yönünde dramatik bir şekilde daralma sergilemiş ve bu daralma da kumaş sıklığını arttırmıştır.

Balıkçı ribana örgü deseninin her iki yüzünde yer alan ask1 ilmekler, kumaş makineden çıkarıldıktan sonra, ilmek çubuklarının saat ibreleri yönünde dönmesine neden olmuştur (Şekil 2). Bu dönmenin neticesinde komşu ilmek çubukları birbiri altına yuvalanarak balıkçı ribana örgü deseninin ilmek yoğunluğunu arttırmıştır. Öte yandan daha az iç gerilimli gevşek kumaş yapısı nedeniyle 1x1 ribana örgü deseni en düşük ilmek yoğunluğunu göstermiştir. 


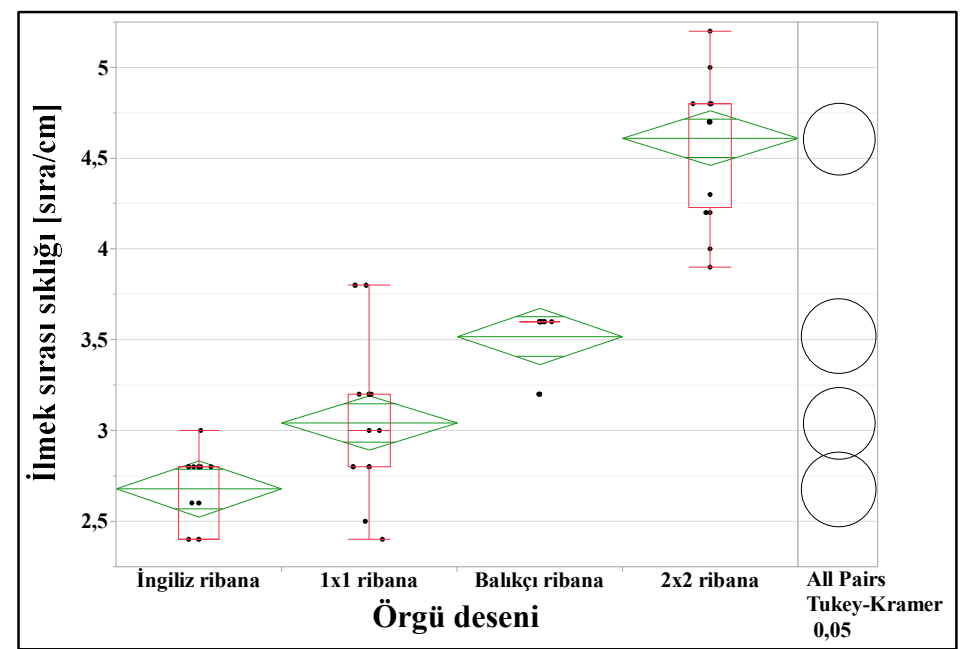

a

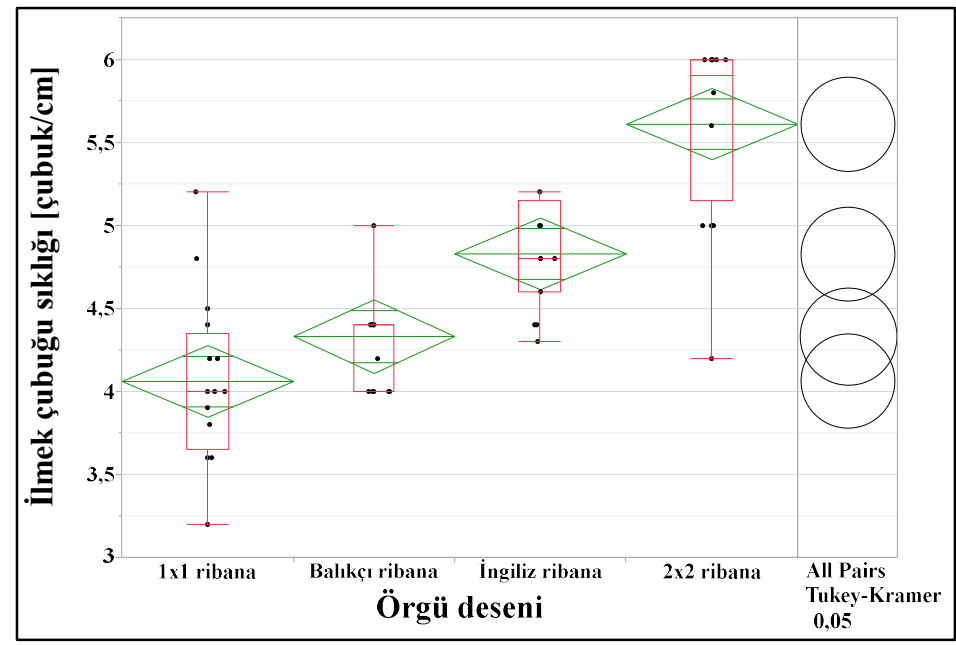

b

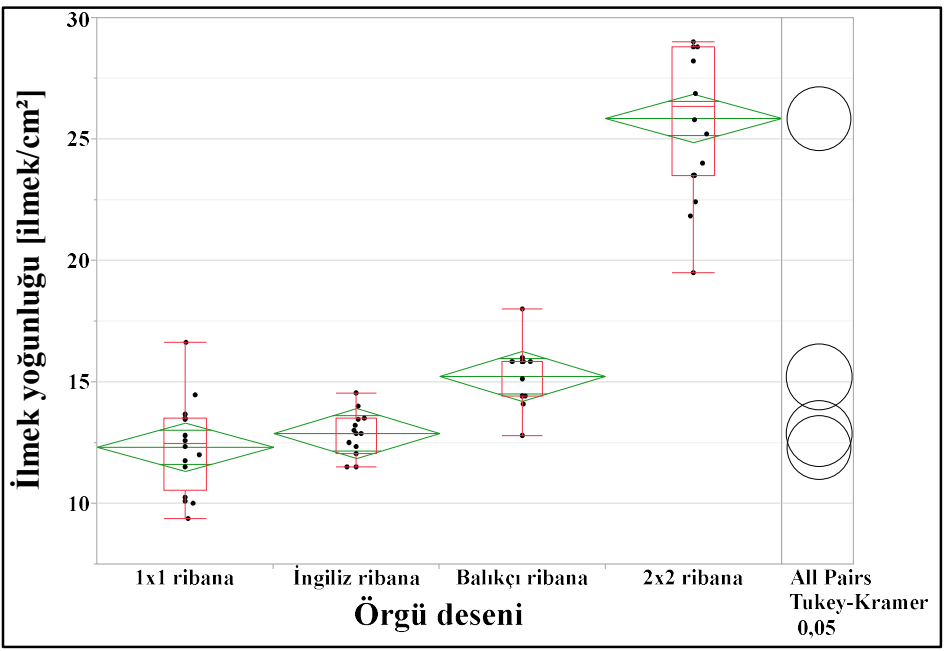

$\mathrm{c}$

Şekil 4. Örgü deseninin ilmek sırası sıklığı (a), ilmek çubuğu sıklığı (b) ve ilmek yoğunluğu (c) üzerine etkisi 
Tablo 2. Örgü deseninin ilmek sırası sıklığı, ilmek çubuğu sıklığı ve ilmek yoğunluğu üzerine etkisi

\begin{tabular}{|c|c|c|c|c|c|c|c|c|c|c|}
\hline Özellik & Örgü deseni & & & & $\mathbf{n}$ & ort & SS & $\overline{A L}$ & $\ddot{\mathbf{U} L}$ & p-değeri \\
\hline \multirow{4}{*}{$\begin{array}{l}\text { İlmek sırası } \\
\text { sıklığ } 1 \\
{[\mathrm{~s} 1 \mathrm{ra} / \mathrm{cm}]}\end{array}$} & $2 \times 2$ ribana & $\mathrm{A}$ & & & 16 & 4,61 & 0,37 & 4,41 & 4,81 & \multirow{4}{*}{$<0,0001$} \\
\hline & Balıkçı ribana & & B & & 15 & 3,52 & 0,17 & 3,43 & 3,61 & \\
\hline & 1x1 ribana & & & $\mathrm{C}$ & 16 & 3,04 & 0,38 & 2,84 & 3,25 & \\
\hline & İngiliz ribana & & & $\mathrm{D}$ & 15 & 2,68 & 0,20 & 2,57 & 2,79 & \\
\hline \multirow{4}{*}{$\begin{array}{l}\text { İlmek çubuğu } \\
\text { sıklığ } \\
{[\text { çubuk/cm] }}\end{array}$} & $2 \times 2$ ribana & $\mathrm{A}$ & & & 16 & 5,61 & 0,54 & 5,32 & 5,90 & \multirow{4}{*}{$<0,0001$} \\
\hline & İngiliz ribana & & B & & 16 & 4,83 & 0,30 & 4,67 & 4,99 & \\
\hline & Balıkçı ribana & & & $\mathrm{C}$ & 15 & 4,33 & 0,33 & 4,15 & 4,51 & \\
\hline & $1 \times 1$ ribana & & & $\mathrm{C}$ & 16 & 4,06 & 0,50 & 3,80 & 4,33 & \\
\hline \multirow{4}{*}{$\begin{array}{l}\text { İlmek } \\
\text { yoğunluğu } \\
{\left[\text { ilmek } / \mathrm{cm}^{2}\right]}\end{array}$} & $2 \times 2$ ribana & $\mathrm{A}$ & & & 16 & 25,86 & 3,09 & 24,22 & 27,51 & \multirow{4}{*}{$<0,0001$} \\
\hline & Balıkçı ribana & & B & & 15 & 15,24 & 1,21 & 14,57 & 15,91 & \\
\hline & İngiliz ribana & & & $\mathrm{C}$ & 15 & 12,90 & 1,02 & 12,33 & 13,46 & \\
\hline & 1x1 ribana & & & $\mathrm{C}$ & 16 & 12,32 & 1,88 & 11,32 & 13,32 & \\
\hline
\end{tabular}

Not: ilmek sırası sıklı̆̆ı: kumaş boyu yönünde $1 \mathrm{~cm}$ mesafede yer alan ilmek sırası sayısı, ilmek çubuğu sıklığı: kumaş eni yönünde $1 \mathrm{~cm}$ mesafede yer alan ilmek çubuğu sayısı, ilmek yoğunluğu: kumaş yüzeyi üzerinde $1 \mathrm{~cm}^{2}$ alanda yer alan toplam ilmek sayısı.

\section{3. İlmek uzunluğu ve "(İlmek yoğunluğu)/(İlmek uzunluğu)" oranı}

İlmek uzunluğu kumaşın fiziksel özelliğini ve kullanım performansını kontrol eden en etkin yapısal parametre olarak karşımıza çıkmaktadır. İlmek kısaldıkça kumaş daha sıkı bir hal almaktadır. Örgü deseni ilmek uzunluğunu istatistiki olarak önemli bir seviyede değiştirmiştir (Şekil 5-a ve Tablo 3). 1x1 ribana deseni en uzun ilmeği sergilerken balıkçı ribana deseni en kısa ilmeği sergilemiştir. İngiliz ve balıkçı ribana desenlerindeki askı ilmeği varlığ ve 2x2 ribana desenindeki kumaş eni yönünde daralma ilmek uzunluğunu kısaltmıştır.

İlmek yoğunluğu artıp ilmek uzunluğu kısaldıkça kumaş daha sıkı bir yapıya bürünmektedir. Dolayısıyla ilmek yoğunluğu ile ilmek uzunluğu arasındaki oran kumaş sıkılığının sayısal bir göstergesi olmaktadır. Örgü deseni "ilmek yoğunluğu/ilmek uzunluğu” oranını istatistiki olarak önemli seviyede etkilemiştir. $2 \times 2$ ribana deseni en yüksek oranı sergilerken $1 \times 1$ ribana deseni en düşüğü sergilemiştir (Şekil 5-b ve Tablo 3). İngiliz ve 1x1 ribana desenleri arasında kumaş sıkılığı oranı açısından istatistiki olarak önemli bir fark gözlemlenmemiştir.
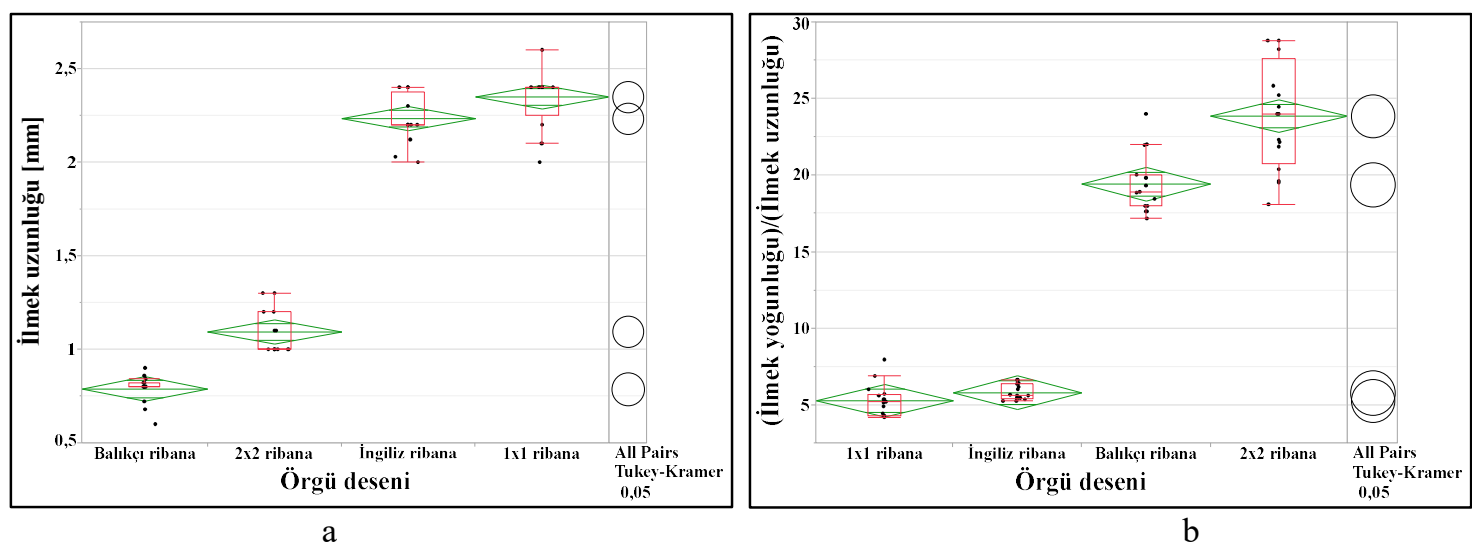

Şekil 5. Örgü deseninin ilmek uzunluğuna (a) ve (ilmek yoğunluğu)/(ilmek uzunluğu) oranına (b) etkisi

Tablo 3. Örgü deseninin ilmek uzunluğuna ve (İlmek yoğunluğu)/(̇lmek uzunluğu) oranına etkisi

\begin{tabular}{|c|c|c|c|c|c|c|c|c|c|}
\hline Özellik & Örgü deseni & & & n & ort & SS & $\mathbf{A L}$ & $\ddot{\mathbf{U} L}$ & p-değ \\
\hline \multirow{4}{*}{$\begin{array}{l}\text { İlmek uzunluğu } \\
\text { [mm] }\end{array}$} & $1 \times 1$ ribana & $\bar{A}$ & & 16 & 2,35 & 0,17 & 2,26 & 2,44 & \multirow{4}{*}{$<0,0001$} \\
\hline & İng & A & & 16 & 2,23 & 0,13 & 2,17 & 2,30 & \\
\hline & $2 \times 2$ ribana & B & & 16 & 1,09 & 0,12 & 1,03 & 1,16 & \\
\hline & $\mathrm{Bal}$ & & $\mathrm{C}$ & 15 & 0,79 & 0,07 & 0,75 & 0,83 & \\
\hline \multirow{4}{*}{$\begin{array}{l}\text { “ïlmek } \\
\text { yoğunluğu/İlmek } \\
\text { uzunluğu” oranı }\end{array}$} & $2 \times 2$ & $\bar{A}$ & & 16 & 2387 & 3,56 & 77 & 25,76 & \multirow{4}{*}{$<0,0001$} \\
\hline & Balıkçı & B & & 15 & 19,42 & 1,93 & 18,36 & 20,49 & \\
\hline & İngiliz ribana & & $\mathrm{C}$ & 15 & 5,81 & 0,50 & 5,53 & 6,09 & \\
\hline & $1 \times 1$ ribana & & $\mathrm{C}$ & 16 & 5,28 & 1,02 & 4,74 & 5,83 & \\
\hline
\end{tabular}




\subsection{Hava Geçirgenliği}

Örgü deseni değiştiğinde hava geçirgenliği değerlerinde net bir şekilde istatistiki olarak anlamlı olan değişimler gözlemlenmiş ve bu gözlemler oldukça düşük p-değerleri ile numerik olarak da desteklenmiştir (Şekil 6 ve Tablo 4). 1x1 ribana deseni en yüksek hava geçirgenliğini sergilerken, 2x2 ribana deseni en düşük hava geçirgenliğini sergilemiştir. Ardışık olarak, öncelikle bitişik iki ters ilmeğin ön iğne yatağında oluşturulması, akabinde yine bitişik iki düz ilmeğin arka iğne yatağında oluşturulması, $2 \times 2$ ribana örgü deseninin diğer desenlere oranla ilmek sırası yönünde daha fazla daralmasına neden olmuştur. Bu dramatik daralma yüksek lif hacmi yüzdesi içerikli, ilmek yoğun, sıkı bir kumaş yapısı oluşturmuş ve kumaşın hava geçirgenliğini düşürmüştür. Öte yandan en düşük lif hacmi yüzdesine ve en düşük ilmek yoğunluğuna sahip gevşek yapılı 1x1 ribana örgü deseni en yüksek hava geçirgenliği performansını sergilemiştir. İngiliz ve balıkçı ribana örgü desenleri arasındaki istatistiksel olarak önemli olan hava geçirgenliği fark1, cam iplik atkılı örme ribana kumaşlarda askı ilmeğinin daha sıkı bir kumaş yapısı oluşturarak hava geçirgenliğini düşürdüğünü kanıtlamıştır.

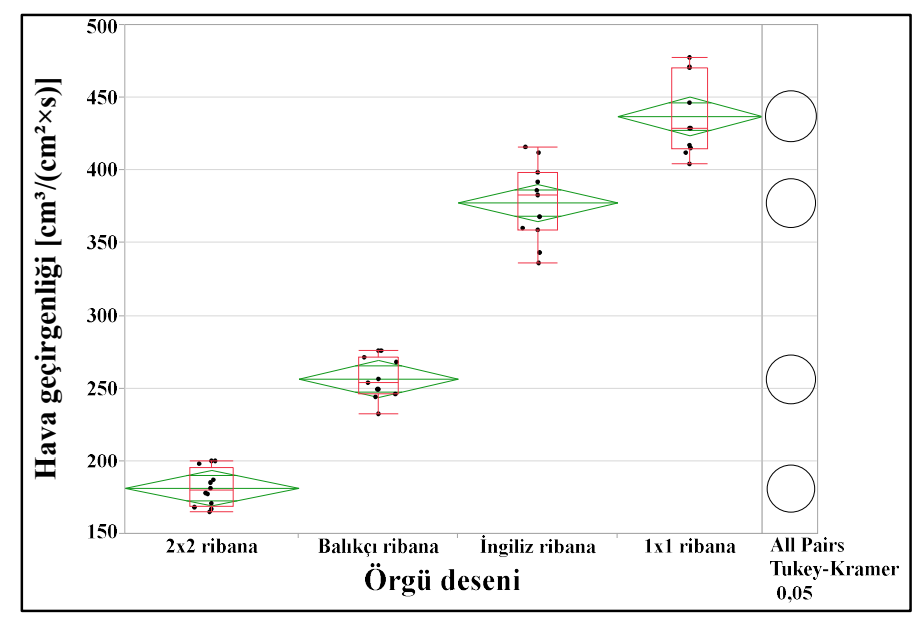

Şekil 6. Örgü deseninin hava geçirgenliği üzerine etkisi

Tablo 4. Örgü deseninin hava geçirgenliği üzerine etkisi

\begin{tabular}{|c|c|c|c|c|c|c|c|c|}
\hline Özellik & Örgü deseni & & n & ort & ss & AL & ÜL & i \\
\hline \multirow{4}{*}{$\begin{array}{l}\text { Hava } \\
\text { geçirgenliği } \\
{\left[\mathrm{cm}^{3} /\left(\mathrm{cm}^{2} \times \mathrm{s}\right)\right]}\end{array}$} & & $\bar{A}$ & 10 & 437, & 27,1 & 417,5 & 456 , & \multirow{4}{*}{$<0,0001$} \\
\hline & İngiliz $\mathrm{r}$ & B & 1 & 37 & 26 , & 359,70 & 395,39 & \\
\hline & Balıkçı ribana & $\mathrm{C}$ & 11 & 256,46 & 14,45 & 246,75 & 266,16 & \\
\hline & $2 \times 2$ ribana & & 12 & 181,42 & 12,82 & 173,27 & 189,56 & \\
\hline
\end{tabular}

Kumaşların ölçülen fiziksel, yapısal ve hava geçirgenliği özellikleri arasında ikili korelasyon analizleri yapılmıştır. Bu analizler sonucunda korelasyon katsayısı (r) mutlak değeri 0,80'in üzerinde olan ilişkiler istatistiksel olarak önemli kabul edilmiştir. Bu bağlamda hava geçirgenliği ile ilmek uzunluğu arasında en yüksek pozitif ilişki $(r=0,87)$ tespit edilirken hava geçirgenliği ile ilmek sırası sıklığı arasında en düşük negatif ilişki $(r=-0,84)$ tespit edilmiştir. Bu sonuçlarla ilgili veriler Şekil 7 ve Tablo 5'de verilmektedir. 

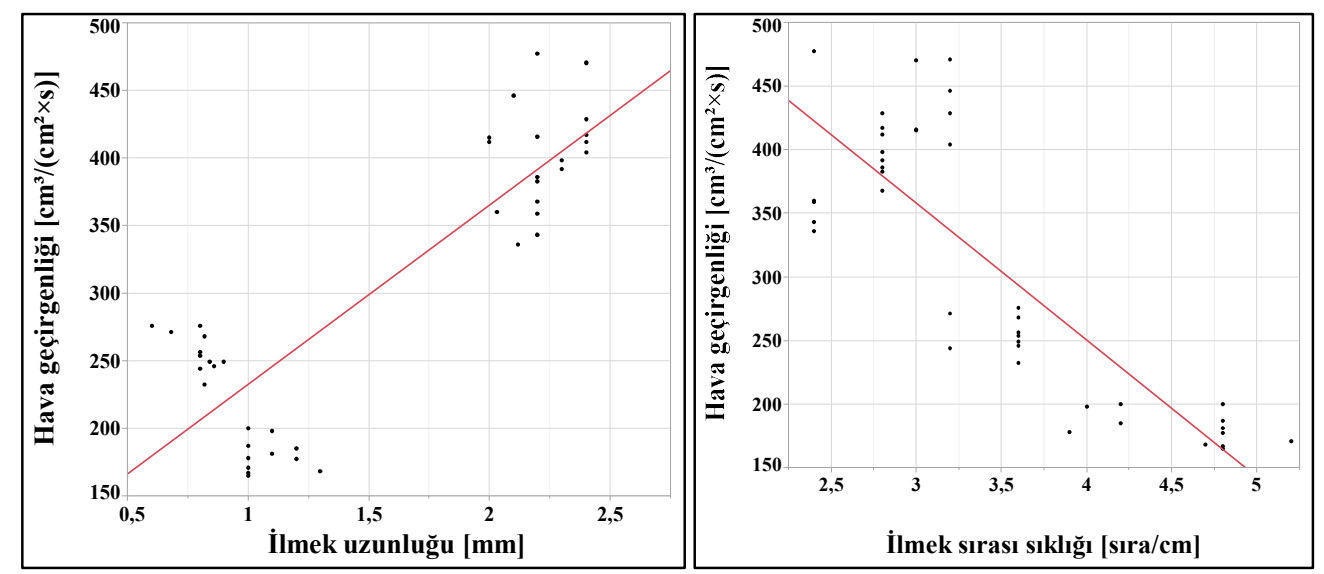

Şekil 7. Hava geçirgenliği ile en yüksek pozitif (a) ve en düşük negatif (b) korelasyon ilişkileri

Tablo 5. Hava geçirgenliği ile en yüksek pozitif ve en düşük negatif korelasyon ilişkileri

\begin{tabular}{lllll}
\hline İlişki & $\mathbf{r}$ & Regresyon denklemi & $\mathbf{R}^{\mathbf{2}}$ & p-değeri \\
\hline İlmek uzunluğu - Hava geçirgenliği & $+0,87$ & $\mathrm{y}=100,14+(132,73) \mathrm{x}$ & 0,75 & $<\mathbf{0 , 0 0 0 1}$ \\
İlmek sırası sıklığ - Hava geçirgenliği & $-0,84$ & $\mathrm{y}=681,20-(107,67) \mathrm{x}$ & 0,70 & $<\mathbf{0 , 0 0 0 1}$ \\
\hline
\end{tabular}

Not: $\mathbf{r}$ : korelasyon katsayısı, $\mathbf{R}^{2}$ : regresyon denklemi kararlılık katsayısı, $\mathbf{r}^{2}=\mathbf{R}^{2}$.

\section{Sonuç ve Öneriler}

Bu çalışmada 3 kat E-camı ipliği kullanarak çift yataklı örme makinesinde farklı desenlerde (1x1, 2x2, İngiliz ve balıkçı ribana desenlerinde) üretilen atkılı örme ribana kumaşların kalınlığı, alansal yoğunluğu, yapısal parametreleri (ilmek sırası sıklığı, ilmek çubuğu sıklığı, ilmek uzunluğu) ve hava geçirgenliği ölçülmüştür. Makineden çıkarılan kumaşlarda en ve boy yönünde gerçekleşen ve miktarları örgü desenine bağlı olarak değişen daralmalar gözlemlenmiştir. Bu daralmalar kumaşların fiziksel ve yapısal özelliklerinin belirlenmesinde rol oynamıştır. Hem makine üzerinde hem de makineden indirildikten sonra ilmek sırası yönünde dramatik bir şekilde daralan ve buna mukabil sıkı bir yapı, yüksek lif içeriği ve yüksek ilmek yoğunluğu sergileyen $2 \times 2$ ribana örgü desenli kumaş en düşük hava geçirgenliğini göstermiştir. Örgü desenine askı ilmeklerin dâhil edilmesi kumaşın sıklığını arttırmış ve hava geçirgenliğini düşürmüştür. Bu çalışma yüksek lif içeriği veya düşük gözeneklilik istenen lif takviyeli kompozit uygulamalarında $2 \times 2$ ribana veya askı ilmek içeren örgü desenlerinin kullanılması gerektiğine işaret etmiştir.

$2 \times 2$ ve balıkçı ribana örgü desenleri en yüksek lif hacmi yüzdesini, en yüksek ilmek yoğunluğunu ve en kısa ilmek uzunluğunu sergilerken $1 x 1$ ribana örgü deseni bu sayılan özelliklerin tam aksini sergilemiştir. Bu bulgular 2x2 ribana örgü deseninin ilmek sırası (kumaş eni) yönündeki daralma eğilimiyle ve balıkçı ribana örgü deseninde ise kumaşın her iki yüzünde yer alan askı ilmeği varlığıyla ilişkilendirilmiştir. Hava geçirgenliği ile ilmek uzunluğu arasında en güçlü pozitif korelasyon tespit edilirken hava geçirgenliği ile ilmek sırası sıklığı arasında ise en güçlü negatif korelasyon tespit edilmiştir.

Üretilen cam iplikli ve muhtelif ribana örgü desenli atkılı örme kumaşlar polyester reçine ile vakum infüzyon metodu kullanılarak muamele edilip atkılı örme kumaş takviyeli polimer matris kompozit malzemeye dönüştürülecektir. Burada, bu çalışma kapsamında elde edilen sonuçlara göre kumaş deseni parametresi kumaşın fiziksel (kalınlık, alansal yoğunluk, lif hacmi oranı) ve yapısal (sıra/çubuk sıklığı, ilmek yoğunluğu, ilmek uzunluğu ve kumaş sıklığı) özelliklerini önemli seviyede etkilemiştir. Kumaş deseni parametresinin kumaş fiziksel ve yapısal özellikleri üzerindeki bu etkisinin bu kumaşlardan üretilen kompozit malzemeye de yansıması beklenmektedir. Bir başka deyişle kumaş deseni parametresini kontrol etme yoluyla atkı1ı örme kumaş takviyeli polimer matrisli kompozitlerde mekanik özelliklerin kontrol edilebileceğinin gösterilmesi planlanmaktadır.

Kumaş sıklığ 1 ve dolayısıyla birim kumaş hacminde yer alan lif miktarı (bir başka deyişle lif hacmi oranı) kumaşın hava geçirgenliği ile ters orantılıdır. Hava geçirgenliğinin düşmesi ile birlikte lif hacmi oranın artması ve buna mukabilde kompozit malzemeden beklenen mekanik özellik performansının artması beklenmektedir. Bu çalışmada ortaya konulan atkı1ı örme kumaşlar kumaş 
takviyeli polimer matris kompozit malzeme üretimine yöneliktir. Bu kapsamda üretilecek kompozit malzemelerin, özellikle yapısal elemanların (arabaların, yel değirmenlerinin, uçakların, deniz taşıtlarının vb.) çarpma darbesine maruz bölgelerinde kullanılması neticesinde, yüksek miktarda çarpma enerjisi emmesi beklenmektedir. Emilecek olan çarpma enerjisi miktarının da kumaş deseni parametresini değiştirme yoluyla kontrol edilebileceğinin gösterilmesi hedeflenmektedir.

\section{Teşekkür}

Bu çalışma Gaziantep Üniversitesi Bilimsel Araştırma Projeleri (BAP) Koordinasyon Birimi tarafından MF.YLT.18.02 nolu ve "Atkılı örme kumaş ile güçlendirilmiş, polimer matrisli kompozit malzeme tasarımı ve üretimi”" başlıklı proje kapsamında desteklenmiştir.

\section{Yazarların Katkısı}

Literatür taraması, deneysel çalı̧̧ma planının hazırlanması, test sonuçlarının istatistiksel olarak analiz edilmesi, grafiklerin çizilmesi, makalenin yazılması ve basıma hazırlanması Mehmet Erdem İnce tarafından yapılmıştır. Kumaşların örülmesi ve testlerin yapılması ise Kıymet Savcı Güneş tarafından yapılmıştır. Bu çalışma Kıymet Savcı Güneş’in yüksek lisans tezinden türetilmiştir.

\section{Çıkar Çatışması Beyanı}

Yazarlar arasında herhangi bir çıkar çatışması bulunmamaktadır.

\section{Araştırma ve Yayın Etiği Beyanı}

Yapılan çalışmada araştırma ve yayın etiğine uyulmuştur.

\section{Kaynaklar}

[1] Kane C.D., Patil U.J., Sudhakar P. 2007. Studies on the influence of knit structure and stitch length on ring and compact yarn single jersey fabric properties. Textile Research Journal, 77 (8): 572-582.

[2] Mikučionienė D., Baltušnikaite J., Milašius R. 2011. Influence of the number of yarns in a loop on the flammability of knits. Fibres \& Textiles in Eastern Europe, 19 (6): 71-74.

[3] Mikučionienė D., Milašiūtė L., Baltušnikaitè J., Milašius R. 2012. Influence of plain knits structure on flammability and air permeability. Fibres \& Textiles in Eastern Europe, 94 (5): 6669.

[4] Mikučionienė D., Milašiūtè L., Milašius R. 2014. Influence of knits structure on flammability and comfortability. AUTEX Research Journal, 14 (4): 226-232.

[5] Bivainyte A., Mikucioniene D. 2011. Investigation on the air and water vapour permeability of double-layered weft knitted fabrics. Fibres \& Textiles in Eastern Europe, 19 (3): 69-73.

[6] Ciobanu L., Filipescu F., 2012. Experimental study on the mechanic behaviour of weft knitted fabrics. Fibres \& Textiles In Eastern Europe, 20 (2): 34-39.

[7] Çoruh E. 2015. Optimization of comfort properties of single jersey knitted fabric. Fibres \& Textiles in Eastern Europa, 23 (4): 66-72.

[8] Ciobanu A. R., Ciobanu L., Dumitras C., Sarghie B. 2016. Comparative analysis of the bursting strength of knitted sandwich fabrics. Fibres \& Textiles in Eastern Europe, 24 (2): 95-101.

[9] Uyanik S., Değirmenci Z., Topalbekiroğlu M., Geyik F. 2016. Examining the relation between the number and location of tuck stitches and bursting strength in circular knitted fabrics. Fibres \& Textiles in Eastern Europe, 24 (1(115)): 114-119.

[10] Uyanık S., Topalbekiroğlu M. 2017. The effect of knit structures with tuck stitches on fabric properties and pilling resistance. Journal of the Textile Institute, 108 (9): 1584-1589.

[11] İnce M. E., Yildirim H. 2019. Air permeability and bursting strength of weft-knitted fabrics from glass yarn. part II: knit architecture effect. The Journal of The Textile Institute, 110 (7): 10721084. 
[12] Ciobanu L., 2011. Development of 3D Knitted Fabrics for Advanced Composite Materials. B. Attaf (Edt.), Advances in Composite Materials - Ecodesign and Analysis, InTech, 161-192.

[13] Gommers B., Verpoest I., Van Houtte P. 1998. Analysis of knitted fabric reinforced composites: part I. fibre orientation distribution. Composites Part A: Applied Science and Manufacturing, 29 (12): 1579-1588.

[14] Pamuk G., Çeken F. 2008. Manufacturing of weft-knitted fabric reinforced composite materials: a review. Materials and Manufacturing Processes, 23 (7): 635-640.

[15] Pandita S. D., Falconet D., Verpoest I. 2002. Impact properties of weft knitted fabric reinforced composites. Composite Science and Technology, 62 (7-8): 1113-1123.

[16] ASTM. (2009). ASTM D3776 Standard Test Methods for Mass Per Unit Area (Weight) of Fabric.

[17] ASTM. (2015). ASTM D8007 Standard Test Method for Wale and Course Count of Weft Knitted Fabrics.

[18] BS. (1988). BS 5441 British Standard Methods of Test for Knitted fabrics.

[19] ASTM. (2018). ASTM D737 Standard Test Method for Air Permeability of Textile Fabrics.

[20] Statistical Software | JMP Software from SAS, 2021. https://www.jmp.com/en_us/home.html 